\title{
Pesquisa de Staphylococcus aureus nas maçanetas das portas dos quartos de um hospital na região Noroeste, Rio Grande do Sul
}

\author{
Silvana Andreia Silva*, Regis Augusto Norbert Deuschle**, Carina \\ de Carvalho Mion Garlet***
}

\begin{abstract}
Resumo: As infecções hospitalares constituem grave problema de saúde pública que contribuem no prolongamento do tempo de internação, aumento de custos e da morbi-mortalidade nessas instituições. De caráter multicausal, agravado pelo fenômeno de resistência microbiana, a situação pode acometer não apenas pacientes, mas também os profissionais de saúde que entrarem em contato com o ambiente contaminado. O S. aureus é um importante patógeno e causador de infecções hospitalares. Devido à possibilidade de sua transmissão via fômites, objetivou-se analisar a freqüência de $\mathrm{S}$. aureus nas maçanetas interna e externa dos quartos de pacientes de um hospital da região Noroeste do Rio Grande do Sul. Foram 78 amostras, 39 internas e 39 externas. Obteve-se 19,23\% de positividade para S. aureus. Quanto ao perfil de resistência antimicrobiana, $73,33 \%$ apresentaram-se sensiveis à oxacilina, 6,67\% intermediários e 20\% resistentes. Quanto a cefoxitina, $86,67 \%$ eram sensiveis, $13,33 \%$ resistentes e nenhum com perfil intermediário.
\end{abstract}

Descritores: Staphyloccocus aureus, Infecção hospitalar, Fômites, Maçanetas.

\section{Research of Staphylococcus aureus in door handles of rooms from a hospital in the northwest region, Rio Grande do Sul}

\begin{abstract}
Hospital infections constitute a serious public health problem, which contribute to the prolongation of hospitalization, and increasing costs, morbidity and mortality in these institutions. Of multicausal character, aggravated by antimicrobial resistance phenomena, the situation may affect not only patients, but also health professionals who come into contact with the contaminated environment. $\mathrm{S}$. aureus is an important pathogen and common cause of nosocomial infections. Considering the possibility of its transmission via fomites, this work analyzed the frequency of $\mathrm{S}$. aureus on the door handles inside and outside the rooms of patients at a hospital in the northwestern region of Rio Grande do Sul. It were collected 78 samples, 39 internal and 39 external. was obtained $19.23 \%$ of positivity for S. aureus. About the resistance profile, $73.33 \%$ were sensitive to oxacillin, $6.67 \%$ intermediate and $20 \%$ resistants. About cefoxitin, $86.67 \%$ were sensitive, resistant and $13.33 \%$ with no intermediate resistance profile.
\end{abstract}

Descriptors: Staphyloccocus aureus, Nosocomial infection, Fomites, Door handles.

\footnotetext{
*Acadêmica do curso de Biomedicina na Universidade de Cruz Alta (UNICRUZ), Cruz Alta, RS, Brasil.

**Professor adjunto no curso de Farmácia na Universidade de Cruz Alta (UNICRUZ), Cruz Alta, RS, Brasil.

${ }^{* * *}$ Coordenadora do curso de Farmácia na Universidade de Cruz Alta (UNICRUZ), Cruz Alta, RS, Brasil.
} 
A microbiota normal é formada por diversos micro-organismos, e diferentes sítios anatômicos possuem perfis microbianos característicos. A flora de cada local possui uma colonização relativamente estável no tempo, em termos dos micro-organismos que a compõe. Entretanto, pode sofrer variações de acordo com fatores genéticos e ambientais. ${ }^{1}$ Em condições normais, não apresentam risco ao hospedeiro. Entretanto, podem se tornar patogênicos em situações de debilidade do sistema imune. ${ }^{2}$

Segundo Cavalcanti et al. (2006), Santos (2000) e Santos e Darini (2002), os indivíduos que possuem agentes primariamente patogênicos integrando sua microbiota podem transmiti-los. Embora não apresentem sintomatologia, constituem o chamado "portador sadio", considerado uma silenciosa e preocupante fonte de contaminação. $3,4,5$

Para Cavalcanti et al. (2006) e Custódio et al. (2009), as mãos de profissionais da saúde podem se tornar uma fonte permanente de agentes primariamente patogênicos, devido à intensa manipulação de pacientes portadores e de fômites hospitalares contaminados por estes. $^{3,6}$

As infecções nosocomiais representam, atualmente, grave problema de saúde pública que contribuem no aumento da mortalidade em ambientes hospitalares. Tal situação pode acometer não apenas pacientes, mas também outras pessoas que entrarem em contato com 0 ambiente contaminado, como profissionais de saúde. , $, 8,9^{2}$

O S. aureus é classificado como uma bactéria altamente patogênica, embora esteja presente como parte da microbiota da maioria dos indivíduos. É causador de diversos gêneros de infecções, tais como endocardites, pneumonias, septicemias entre outras. Pode ser encontrado em diversos sítios anatômicos, sendo os principais a cavidade nasal e as mãos. ${ }^{3,4,5}$

Tal bactéria, além de ser uma das causas mais comuns de infecções nosocomiais, pode, ainda, evidenciar resistência aos antimicrobianos; o fenômeno pode ser mediado por plasmídeos ou codificado cromossomicamente. Para o S. aureus, são três os mecanismos de resistência a meticilina: modificações na capacidade de ligação às proteínas ligadoras de penicilina (protein binding penicilin - PBP), hiperprodução de beta-lactamases e produção de uma PBP alterada denominada PBP2a, codificada cromossomicamente pelo gene mecA. Estes isolados são chamados de $\mathrm{S}$. aureus meticilina resistentes (MRSA). ${ }^{10}$ Fatores como internação em unidades de terapia intensiva (UTIs), hospitalização prolongada, procedimentos invasivos e exposição repetida a antibióticos propiciam o contato com 0 agente. ${ }^{11,12,13}$

A presença de determinados micro-organismos em fômites hospitalares pode indicar condições higiênico-sanitárias insatisfatórias, representando, também, uma importante fonte de transmissão de enfermidades. ${ }^{14}$ Frente a isso, o presente trabalho tem o propósito de analisar a presença de $\mathrm{S}$. aureus nas maçanetas das portas dos quartos hospitalares, por ser um fômite que proporciona, de forma facilitada, a transmissão de tal agente infeccioso. Diante do exposto, este estudo procurou verificar ocorrência de $S$. aureus e MRSA em maçanetas das portas dos quartos com internação via SUS e internação via convênios /

Saúde (Santa Maria), v.38, n.1, p. 129-138, 2012. Pequisa de Staphylococcus aureus nas maçanetas las portas dos quartos de um hospital na região Noroeste, Rio Grande do Sul ISSN 2236-5834 particular de um hospital da região noroeste do Estado do Rio Grande do Sul, comparando os resultados entre as duas alas e alertar a comunidade hospitalar sobre a importância da lavagem das mãos e limpeza das maçanetas para o controle da infecção nosocomial. 
0 estudo foi realizado no período de agosto a setembro de 2010. Fizeram parte 39 quartos, totalizando 78 maçanetas, 39 internas e 39 externas aos quartos de um hospital de médio porte do Noroeste do Estado do Rio Grande do Sul. As amostras constituíram-se de 32 maçanetas da ala Convênio / Particular, sendo 16 internas e 16 externas aos quartos, e 44 amostras da ala SUS, 22 internas e 22 externas às portas dos quartos. Foram amostradas ainda 2 maçanetas da porta da maternidade, incluídas na ala SUS. As amostras foram coletadas com swab umedecido em caldo infusão de cérebro e coração (Brain Heart Infusion - BHI), e imediatamente transportadas ao laboratório após a coleta e incubadas em caldo BHI por 12 horas em estufa a $35^{\circ} \mathrm{C}$.

Após o período de incubação, adotou-se para a identificação das bactérias a metodologia de Koneman et al (2001),sendo submetidas à semeadura em ágar sal-Manitol . As amostras que evidenciaram a característica fermentação do meio foram submetidas à coloração de Gram para visualização da morfologia bacteriana e ao teste da catalase, para identificação da família. ${ }^{2}$ Em seguida, com as amostras catalase positivas, realizou-se o teste da coagulase livre, para identificação das espécies de Staphylococcus aureus. ${ }^{2}$

Como última etapa, realizou-se teste de suscetibilidade antimicrobiana por método de disco-difusão frente a oxacilina e cefoxitina conforme preconizado pelo CLSI. ${ }^{15}$

Todos os meios de cultura utilizados eram da marca Biobrás ${ }^{\circledR}$.

A análise dos resultados se baseou em freqüência e percentual e comparação de grupos através do teste do Qui-quadrado.

\section{Resultados}

Das 78 maçanetas, $15(19,2 \%)$ tiveram resultado positivo para S. aureus. A tabela 1 apresenta freqüência e percentual de positividade e negatividade para $S$. aureus relacionadas às alas Convênio/Particular e SUS.

Da ala Convênio / Particular, quatro (12,5\%) das 32 maçanetas apresentaram positividade para S. aureus. Das 46 maçanetas da ala SUS, $11(23,9 \%)$ foram positivas para a referida bactéria. Embora a ala SUS tenha apresentado um maior número de maçanetas contaminadas em relação à ala Convênio/Particular, esta diferença apresentou $p>0,05$, não sendo estatisticamente significativa. 
Tabela 1 - Freqüência e percentual de contaminação por S. aureus nas alas Convênio/Particular e SUS.

\begin{tabular}{c|c|c|c|c}
\multicolumn{2}{c|}{} & \multicolumn{2}{c|}{ Condição } & Nogativo \\
\hline Convênio e & Ala & 28 & 4 & 32 \\
Particular & \% Ala & $87,5 \%$ & $12,5 \%$ & $100,0 \%$ \\
& & & & \\
\hline SUS & (n) & 35 & 11 & 46 \\
& $\%$ Ala & $76,1 \%$ & $23,9 \%$ & $100,0 \%$ \\
& (n) & 63 & 15 & 78 \\
& \% Ala & $80,8 \%$ & $19,2 \%$ & $100,0 \%$ \\
\hline
\end{tabular}

$\mathrm{Na}$ tabela 2, observa-se que das 11 maçanetas internas positivas, duas $(18,2 \%)$ foram da ala Convênio/Particular, e nove $(81,8 \%)$ da ala SUS. Das 4 maçanetas externas positivas, duas (50\%) foram da ala Convênio/Particular e duas (50\%) da ala SUS. Não se observou significância estatística $(p>0,05)$ nestes grupos comparados.

Tabela 2 - Freqüência e percentual de contaminação das maçanetas internas e externas aos quartos das alas Convênio/Particular e SUS.

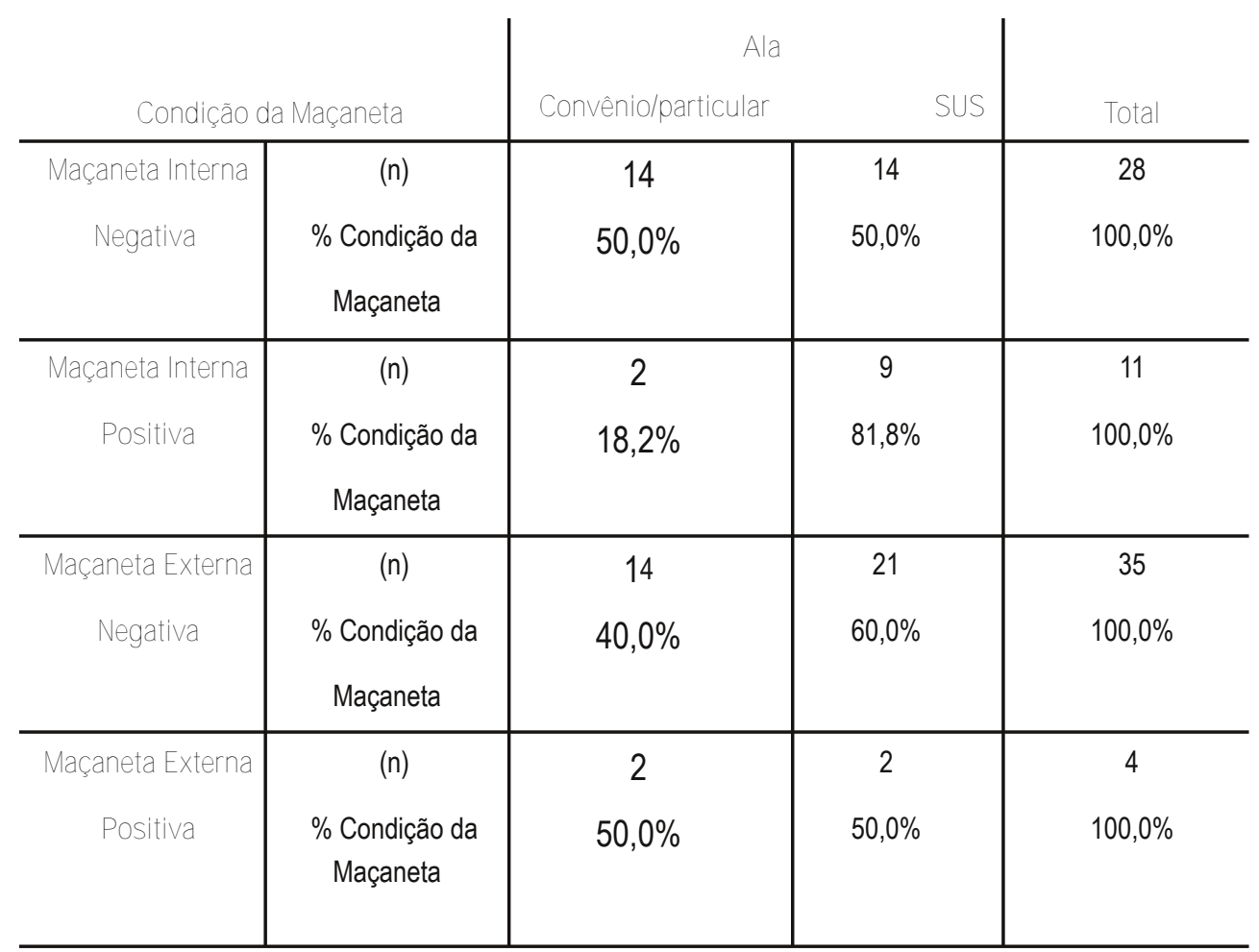

Quanto ao perfil de suscetibilidade antimicrobiana, das 15 amostras positivas, 11 $(73,33 \%)$ apresentaram-se sensíveis à oxacilina, uma $(6,67 \%)$ apresentou-se intermediária e

Saúde (Santa Maria), v.38, n.1, p. 129-138, 2012. Pesquisa de Staphylococcus aureus nas maçanetas das portas dos quartos de um hospital na região Noroeste, Rio Grande do Sul ISSN 2236-5834 três $(20 \%)$ apresentaram-se resistentes.

Quanto à cefoxitina, $13(86,67 \%)$ apresentaram sensibilidade ao medicamento, duas $(13,33 \%)$ mostraram-se resistentes e nenhuma amostra apresentou-se intermediária.

Tais resultados podem ser visualizados na tabela 3 . 
Tabela 3 - Perfil de suscetibilidade à oxacilina e cefoxitina.

\begin{tabular}{|c|c|c|c|c|}
\hline Casos Positivos & Sensível & Intermediário & Resistente & Total \\
\hline (n) & 11 & 1 & 3 & 15 \\
\hline OXA (\%) & $73,3 \%$ & $6,7 \%$ & $20 \%$ & $100,0 \%$ \\
\hline CFO (n) & 13 & 0 & 2 & 15 \\
\hline$(\%)$ & $86,67 \%$ & $0 \%$ & $13,33 \%$ & $100,0 \%$ \\
\hline
\end{tabular}

Conforme as tabelas 4 e 5, na ala Convênio/Particular, obteve-se quatro casos positivos, e destes, dois (50\%) apresentaram sensibilidade à oxacilina e $2(50 \%)$ apresentaram resistência, ocorrendo em igual proporção com a cefoxitina. Ambos os medicamentos tiveram $0 \%$ de casos intermediários. Na ala SUS, dos 11 casos positivos, obtiveram-se nove $(81,82 \%)$ sensíveis a oxacilina, um $(9,09 \%)$ intermediário e um $(9,09 \%)$ resistente. O perfil de suscetibilidade à cefoxitina apresentou-se sensível em 11 (100\%) amostras. A diferença entre as duas alas e a sensibilidade à cefoxitina foi estatisticamente significativa ao nível de significância $p=0,012$.

Tabela 4 - Perfil de Suscetibilidade à Oxacilina.

\begin{tabular}{cc|cccc}
\hline \multicolumn{2}{c|}{ Ala } & \multicolumn{4}{c}{ OXA } \\
& & Sensível & Intermediário & Resistente & Total \\
\hline Convênio e & (n) & 2 & 0 & 2 & 4 \\
Particular & $\%$ Condição & $50 \%$ & $0 \%$ & $50 \%$ & $100,0 \%$ \\
SUS & (n) & 9 & 1 & 1 & 11 \\
& \% Condição & $81,82 \%$ & $9,09 \%$ & $9,09 \%$ & $100,0 \%$ \\
\hline
\end{tabular}

Tabela 5 - Perfil de Suscetibilidade à Cefoxitina.

\begin{tabular}{cc|cccc}
\hline & & \multicolumn{4}{c}{ OXA } \\
& & Sensível & Intermediário & Resistente & Total \\
\hline Convênio e & (n) & 2 & 0 & 2 & 4 \\
Particular & $\%$ Condição & $50 \%$ & $0 \%$ & $50 \%$ & $100,0 \%$ \\
Sus & (n) & 11 & 0 & 0 & 11 \\
& \% Condição & $100 \%$ & $0 \%$ & $0 \%$ & $100,0 \%$ \\
\hline
\end{tabular}

\section{Discussão}

A capacidade de adaptação de um micro-organismo ao estresse ambiental é um Saúde (Santa Maria), v.38, n.1, p. 129-138, 2012. Silva, S. A.; Deusche, R. A. N.; Garlet, C. C. M. importante fator para a sua sobrevivência e disseminação no meio ambiente. 
A viabilidade bacteriana pode ser mantida por até 14 dias na ausência de material orgânico, e este período pode ser prolongado se houver presença de sangue, saliva ou outros fluidos biológicos. ${ }^{16}$

O S. aureus também pode colonizar diferentes sítios anatômicos do corpo de toda a comunidade hospitalar, incluindo profissionais da saúde, pacientes e visitantes. Em trabalho de Santos e Darini (2002), foi avaliada a colonização de S. aureus nas mãos de funcionários de um hospital, tendo sido encontrada uma média de $29,95 \%$. Destes mesmos funcionários foi encontrado $40,6 \%$ de $\mathrm{S}$. aureus nas fossas nasais. Foram também avaliados os mesmos sítios anatômicos dos responsáveis pelos pacientes, e encontrou-se uma média de 30,7\% da bactéria nas mãos e $37,5 \%$ nas fossas nasais. Isso indica que as fossas nasais são fonte de contaminação para outras superfícies cutâneas do portador são. Considerando tais fatos e sendo a maçaneta um fômite de intensa manipulação, a possibilidade de contaminação através desta é elevada. ${ }^{5}$ Carvalho (2007) observou 3,8\% de contaminação por S. aureus nas maçanetas de um hospital de Uberlândia, com $p=1,00$. Também pôde ser observada contaminação em outros locais, como piso, grade da cama e mesa, com percentuais de $38,5 \%, 15,4 \%$ e $11,5 \%$, respectivamente. Para estes resultados, foram obtidos valores de $p>0,05 .{ }^{7}$ Este nível de significância foi semelhante ao do presente estudo, onde encontrou-se $19,2 \%$ de contaminação do total de maçanetas. Tal dado merece atenção devido à reconhecida patogenicidade do S. aureus e pela possibilidade do paciente internado se apresentar em condições imunológicas deficitárias. É preciso levar em consideração ainda o aspecto do portador silencioso, pela possibilidade de disseminação do micro-organismo ou mesmo do próprio portador vir a sofrer doença cuja morbidade seja aumentada pela presença do $\mathrm{S}$. aureus. No presente estudo, os ocupantes dos quartos não foram avaliados quanto às patologias de base que os acometiam, outro fator que pode muitas vezes estar relacionado à colonização.

Observou-se, no estudo, que a ala com maior freqüência de positividade para S. aureus foi a ala SUS, com $23,9 \%$ de positividade. Embora o estudo não tenha avaliado fatores de risco, uma explicação hipotética para essa maior freqüência poderia ser o tipo de quarto, que nesta ala são, em grande parte, coletivos, havendo portanto maior fluxo de pessoas, maior número de acompanhantes e entrada e saída de funcionários. Deste modo, questões relativas à higienização também ficam dificultadas, o que facilitaria a propagação e manutenção do S. aureus e outros micro-organismos nas superfícies. Observa-se, ainda, que, tanto nesta ala quanto em relação ao total dos fômites analisados, o maior percentual de positividade foi para as maçanetas internas, embora, sem significância estatística $(p>0,05)$. Tal situação não deixa de ser preocupante. As maçanetas internas fazem parte do ambiente interno do quarto, ficando mais tempo disponível para contato tanto para os trabalhadores de saúde que ali entram quanto para os acompanhantes que lidam com o doente e mais próximo ao próprio doente em si. Levanta-se a possibilidade, também, dos índices de contaminação por S. aureus encontrados no presente trabalho serem oriundos do fluxo do ar, podendo justificar, inclusive, a maior contaminação na ala SUS. Um estudo teve como amostragem 0 ar de diversos setores de um hospital do Estado de São Paulo. Foram coletados 500 litros de ar por impacto durante 5 minutos sobre placas de Agar Manitol para identificação de $\mathrm{S}$. aureus, e outros meios para identificação de outras bactérias. As maiores

Saúde (Santa Maria), v.38, n.1, p. 129-138, 2012. de Staphylococcus aureus nas maçanetas Noroeste, Rio Grande do Sul concentrações de bioaerossóis bacterianos foram detectadas em locais naturalmente ventilados e com maior ocupação. O S. aureus foi detectado em $50 \%$ destes ambientes. 
Concentrações menores foram detectadas em locais com apenas um ocupante. Os autores destacam que o aumento do número de bioaerossóis deve-se, entre outras, às atividades exercidas pelos ocupantes, que podem levar à emissão ou suspensão de partículas. ${ }^{17}$

Em relação ao perfil de resistência à oxacilina, observou-se uma alta porcentagem no estudo em relação ao total de positivos. Os valores encontrados são similares ou acima de outros que foram verificados na literatura. Cabe ressaltar um estudo onde pôde se observar $41 \%$ de colonização por S. aureus na saliva de trabalhadores de um hospital. Destes, 29,6\% apresentaram sensibilidade e 7,1\% apresentaram perfil resistente à meticilina. ${ }^{18}$

Embora os valores de $p$ neste caso não sejam significativos, deve-se levar em conta que organismos resistentes são motivo de cuidados redobrados em ambiente hospitalar pelo sensível aumento da morbi-mortalidade que são capazes de causar. A recente mudança na normatização da venda de antimicrobianos e a explosão na mídia de notícias relacionadas à resistência bacteriana são reflexo direto dos riscos que a presença de tais micro-organismos envolve. Portanto, embora o nível de $\mathrm{S}$. aureus resistente à oxacilina encontrado neste trabalho não seja significativo, não implica que cuidados habituais de higienização e de medidas contra a proliferação bacteriana devam ser descartados ou considerados de maneira superficial.

A CLSI (Clinical and Laboratory Standards Institute) de 2006 recomenda o uso da cefoxitina para a detecção de MRSA. Estudos compararam a eficácia de identificação MRSA com discos de oxacilina e cefoxitina, e os resultados da cefoxitina foram compatíveis com 0 PCR (padrão ouro para identificação de cepas resistentes devido à detecção do gene $M e c \mathrm{~A}$ ). Este estudo ainda relata que a oxacilina não é eficaz na deteç̧ão de casos borderline, devido à baixa expressão gênica das cepas. Embora a literatura sugira a utilização do método de disco-difusão com o uso de cefoxitina, por ser mais sensível na detecção de MRSA do que com a oxacilina, os resultados neste estudo mostraram evidência em contrário. ${ }^{19,} 20,21$

\section{Conclusões}

O estudo demonstrou, de maneira inequívoca, a presença do micro-organismo nas maçanetas dos quartos de diferentes alas do hospital estudado. Tal constatação é compatível com a literatura, na qual se relata a ampla distribuição do $\mathrm{S}$. aureus, tanto em fômites como nos ambientes e em indivíduos que o carregam na condição de portador.

Quanto à resistência antimicrobiana, foi possível constatar que as maçanetas internas apresentaram maior frequência de positividade para a presença de $S$. aureus, podendo ser justificado pelo exposto acima.

Sugerem-se mais estudos que correlacionem a questão maçanetas contaminadas versus patologia de base do paciente. Embora o nível de contaminação para S. aureus nas maçanetas $(19,2 \%)$ tenha ficado entre valores previamente relatados na literaturaa ${ }^{7,22}$, enfatizase a constante atenção a procedimentos que minimizem a presença do micro-organismo em fômites, tais como: a frequente lavagem das mãos, cuidados no manuseio de fômites, especialmente os do tipo invasivo (como catéteres) e atenção na higienização de superfícies frequentemente manuseadas, como as maçanetas das portas. Tendo em vista que no 
o uso de oxacilina, verifica-se a necessidade de mais estudos comparativos entre os dois métodos para determinar com fidedignidade a real capacidade destes dois antimicrobianos para o fim a que se propõe.

\section{Referências}

1. Parfrey LW, Knight R. Spatial and temporal variability of the human microbiota. Clin Microbiol Infect. 2012; 18(4): $5-7$.

2. Koneman E W, Allen SD, Janda, WM, Schreckenberger PC, Winn WC. Diagnóstico Microbiológico. $5^{a}$ ed. Rio de Janeiro: Medsi, 2001.

3. Cavalcanti SMM, França ER, Vilela MA, Montenegro F, Cabral C, Medeiros ACR. Estudo Comparativo da Prevalência de Staphylococcus aureus Importado das Unidades de Terapia Intensiva de Hospital Universitário, Pernambuco, Brasil. Rev Bras Epidemiol. 2006; 9(4): 436 - 446.

4. Santos BMO. Monitoramento da Colonização pelo Staphylococcus aureus em Alunos de um Curso de Auxiliar de Enfermagem Durante a Formação Profissional. Rev Latino-am Enfermagem. 2000; 8(1): 67 - 73.

5. Santos BMO, Darini ALC. Colonização por Staphylococcus aureus em Portadores Sãos Relacionados de uma Creche de Hospital Universitário. Medicina, Ribeirão Preto. 2002; 35: 160 - 172.

6. Custódio J, Alves JC, Silva FM, Dolinger EJO, Santos JGS, Brito DD. Avaliação Microbiológica das Mãos de Profissionais da Saúde de um Hospital Particular de Itumbiara, Goiás. Rev Ciênc Méd. 2009 ; 18 : 7 - 11.

7. Carvalho KS, Melo MC, Melo GB, Gontijo-Filho PP.Hospital contamination in wards occupied by patients infected with MRSA or MSSA in a Brazilian university hospital. Rev Ciênc Farm Básica Apl. 2007 ; 28(2):159163.

8. Pina E, Silva MG, Silva EG, Uva AS. Infecção relacionada com a prestação de cuidados de saúde : infecções da corrente sanguínea (septicemia). Rev Port Sau Pub. 2010 ; 28(1): 19 - 30.

9. Vilela R, Dantas SRPE, Trabasso P. Equipe interdisciplinar reduz infecção sanguínea relacionada ao cateter venoso central em Unidade de Terapia Intensiva Pediátrica. Rev Paul Pediatr. 2010 ; 28(4) : 292 298.

10. Souza MV, Reis C, Pimenta FC. Revisão sobre a aquisição gradual de resistência de Staphylococcus aureus aos antimicrobianos. Rev Pat Trop. 2005 ; 34(1) : 27 - 36.

11. Gelatti, LC, Sukiennik T, Becker AP, Inoue FM, Carmo MS, Castrucci FMS et al . Sepse por Staphylococcus aureus Resistente à Meticilina Adquirida na Comunidade do Sul do Brasil. Rev Soc Bras Med Trop. 2009 ; 42(4): $458-460$.

12. Gelatti LC, Bonamigo RR, Becker AP, d'Azevedo PA. Staphylococcus aureus Resistente à Meticilina: Disseminação Emergente na Comunidade. An Bras Dermatol. 2009 ; 84(5) : 501 - 506.

13. Martins Junior PO, Porto ER, Silva RN, Pinhati HMS. Prevalência de Staphylococcus aureus Resistente à Meticilina, Isolado em Hemoculturas de Pacientes Internados em Alguns Hospitais do Distrito Federal, Brasil. Brasilia Med. 2009 ; 46(2): 125 - 130.

14. Alves CFV, Santos RT, Lolli RR, Soares MCB. Condições Higiênico-sanitárias de Telefones Públicos no Município de Santos. News Lab. 2007; 82:192 - 200.

15. Clinical and Laboratory Standards Institute. Performance standards for antimicrobial susceptibility testing. CLSI approved standard M100-S15. Clin Lab Stand Inst. 2008.

Saúde (Santa Maria), v.38, n.1, p. 129-138, 2012. esquisa de Staphylococcus aureus nas maçanetas las portas dos quartos de um hospital na região Noroeste, Rio Grande do Sul ISSN 2236-5834
16. Rossi, D. et al. Influência de fluídos Biológicos na sobrevivência de Staphylococcus aureus sobre diferentes superfícies secas. Revista De Ciências Farmacêuticas Básica E Aplicada. 2008; 29: 211 - 214.

17. Pereira RG, Reis D, Ambrósio Júnior GN, Raddi MSG, Pedigone MAM, Martins CHG. Bioaerossóis Bacterianos em um Hospital. Rev Ciênc Farm Básica Apl. 2005; 26(1): 77 - 81. 
18. Moura JPA. Colonização dos Profissionais da Enfermagem por Staphylococcus aureus: Problemática e Desafios. Ribeirão Preto: [s.n], 2009. Tese (Doutorado) - Universidade de São Paulo. Escola de Enfermagem, 2009.

19. Anand, KB, Agrawal P, Kumar S, Kapila K. Comparison of Cefoxitin Disc Diffusion Test, Oxacillin Screen Agar, and PCR for mecA gene for Detection of MRSA. Indian J Med Microbiol. 2009; 27(1): 27 - 29.

20. Perez LRR, Dias C, d'Azevedo PA. Agar dilution and agar screen with cefoxitin and oxacillin: what is known and what is unknown in detection of meticillin-resistant Staphylococcus aureus. J Med Microbiol. 2008; $57(8): 954-956$.

21. Valesco D, Tomas MDM, Cartelle M, Beceiro A, Perez A, Molina F et al. Evaluation of Different Methods for Detecting Methicillin (oxacillin) Resistance in Staphylococcus aureus. J Antimicrob Chemother. 2005; 55(3): $379-382$.

22. Oie S, Hosokawa I, Kamiya A. Contamination of room door handles by methicillin-sensitive/methicilinresistant Staphylococcus aureus. J Hosp Infect. 2002; 51(2): 140 - 143.

\section{Carina de Carvalho Mion Garlet}

Endereço para correspondência - Rodovia Municipal Jacob Della Méa, Km 5.6, Parada Benito.

Centro de Ciências da Saúde - Curso de Farmácia - Campus Universitário Dr. Ulysses Guimarães -CEP 98.020-290 - Cruz Alta/RS

E-mail: cmion@unicruz.edu.br

Currículo lattes: http://lattes.cnpq.br/1376991307264684

Recebido em 05 de dezembro de 2011

Aprovado em 03 de agosto de 2012. 
Saúde (Santa Maria), v.38, n.1, p. 129-138, 2012. Pesquisa de Staphylococcus aureus nas maçanetas das portas dos quartos de um hospital na região Noroeste, Rio Grande do Sul 